\title{
Cfd Simulation and Experimentalverification of Air Flow through Heated Pipe
}

\author{
Jamuna A B ${ }^{1}$, Somashekar $\mathrm{V}^{2}$ \\ ${ }^{1}$ Asst. Professor, Department of Aeronautical Engineering, Visvesvaraya Technological University, India \\ ${ }^{2}$ Asst. Professor, Department of Aeronautical Engineering, Visvesvaraya Technological University, India
}

\begin{abstract}
The aim of this work is to validate the Dittus-Boelter equation by experimental,correlation and Simulation method. It used to find the value of heat transfer coefficient ' $h$ ' for turbulent flow in many fluid transfer systems. This work discusses how the Dittus-Boelter equation is applied to the problem of circular pipe. In CFD simulation ICEM CFD for modeling and CFX13 for analysis are used. Results of CFD simulation will be obtained by CFD-POST. Here heat transfer coefficient value is compared by correlations,experiment and CFD simulations, finally the aim of this work is to validate Dittus-Boelter equation.
\end{abstract}

Key words: CFD, Correlation Method, Experimental Method, Heat Transfer Coefficient, Simulation Method.

\section{Introduction}

In the study of thermodynamics the average heat transfer coefficient, is used in calculating the convection heat transfer between a moving fluid and a solid. This is the single most important factor for evaluating convective heat loss or gain. Knowledge of $h$ is necessary for heat transfer design and calculation and is widely used in manufacturing processes, oil and gas flow processes and air-conditioning and refrigeration systems. The heat transfer coefficient is critical for designing and developing better flow process control resulting in reduced energy consumption and enhanced energy conservation.

It is also influenced by flow velocity and surface geometry. It may be noted that the physical or thermal properties of the surface material play no part in the process of convective heat transfer. As the fluid properties vary with the temperature and locations the value of convective heat transfer coefficient vary from point to point, this leads to the situation that analytically derived equation are applicable only to a limited extent. [1]

\subsection{Dittus Boelter relation}

The conventional expression for calculating the heat transfer coefficient in fully developed turbulent flow in smooth pipes is the Dittus-Boelter equation.

$$
N_{u}=C R_{e} m P_{r} n
$$

Where $C, m$ and $n$ are constant determined experimentally. We will use these values -

$C=0.023, m=0.8$ and

$n=0.4$ for heating of the fluid

$n=0.3$ for cooling of the fluid

The properties of this relation have been calculated at the average fluid bulk temperatures. Equation is valid for single phase heat transfer in fully developed turbulent flows in smooth pipes for fluids with Prandtl number ranging from 0.6 to 100 at low heat fluxes. At high fluxes the fluid properties changes resulting in higher errors. At higher heat fluxes the Sieder-Tate equation is used to reduce the error. The work presented is about designing and acquiring data from an experimental setup to verify the Dittus-Boelter empirical relation by finding the heat transfer coefficient. The value of the heat transfer coefficient has been calculated from theory, experiment and CFD simulation to compare the results. This research work uses different approaches to calculate two very important performance considerations, heat transfer rate and pressure drop in turbulent duct flow, using $R_{e} P_{r}$ and $N_{u}$. [1]

For laminar flow in pipes the heat transfer coefficient $(h)$ can be found by solving the governed differential equations analytically. But in the case of turbulent flow things become chaotic and it is impossible to solve differential equation analytically.

For turbulent flow we rely on experiments and develop correlations. One such correlations Dittus-Boelter equation. 


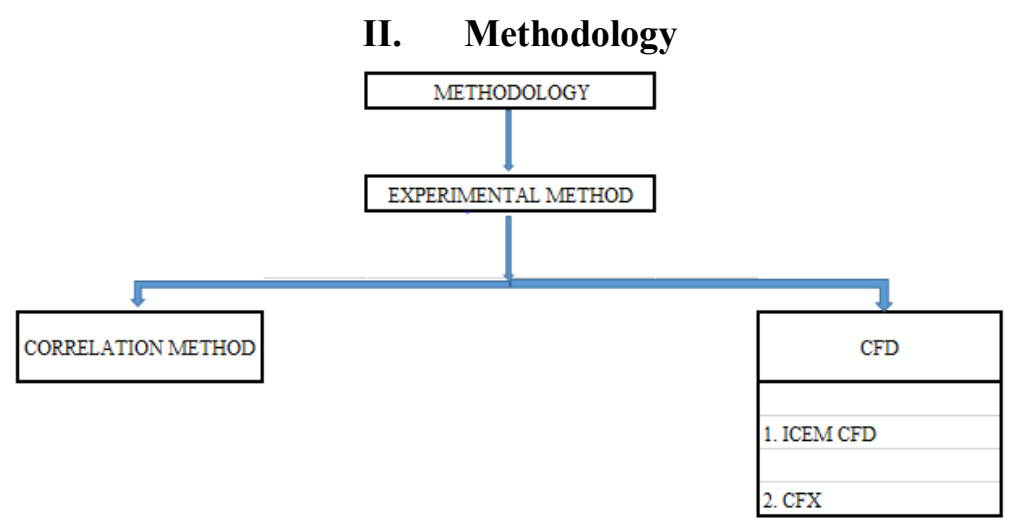

The above flow chart represents the step by step working procedure of this work. Thestandard procedure for ICEM-CFD work follows the above components. For the present work, in case of pipe creating the geometry then computational domain is constructed around the pipe geometry, later set the mesh parameters then generates the mesh. Later this mesh is exported in the fluent readable format.

Thestandard procedure for ANSYS CFX work follows the above components. For the present work, in this case to ensure that 3D, later this mesh file is imported into ANSYS CFX for analysis. In the CFX, the analysis will be carried out. The post processing is carried according to the requirements. [2]

\subsection{Experimental Set Up}

\section{Experimental Set Up Of Forced Convection}

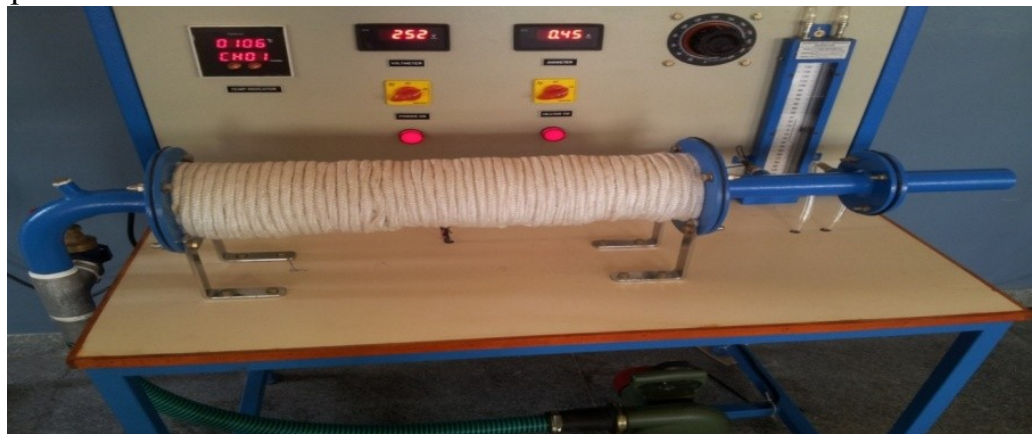

Fig. 3.1:Experimental Set Up Of Forced Convention

The experimental set up consists of a blower unit fitted with the rest pipe. The test section pipe is copper surrounded by band heater. Six thermocouples are embedded on the test section and two thermocouples are placed in the air stream at the entrance and exit of the test section to measure air inlet and outlet temperature. Test pipe is connected to the delivery side of blower along with orifice to measure flow of air through the pipe. Input to the heater through dimmer stat and measured by voltmeter and ammeter. Air flow is controlled by gate valve and is measured with the help of orifice meter and the manometer fitted on board.

\section{Specifications:}

Length of hallow pipe $=500 \mathrm{~m}$

Pipe inner diameter $=0.038 \mathrm{~m}$

Orifice diameter $=0.025 \mathrm{~m}$

\subsection{Lay Out Of Experimental Set Up}

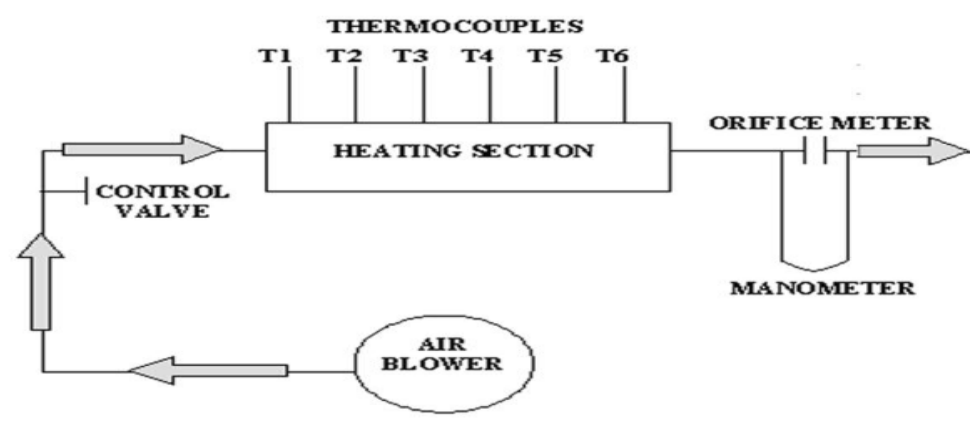

Figure 3.2: Lay Out Of Experimental Set Up 


\subsection{Calculation of Heat Transfer Coefficient}

Results obtained by experimental set up

For heat input of 80 watts $\left(1350 \mathrm{w} / \mathrm{m}^{2}\right)$.

$$
\begin{gathered}
T_{1}=85 c, T_{2}=88 c, T_{3}=90 c, T_{4}=91 c, T_{5}=92 c, T_{6}=92 c \\
T_{\text {air inlet }}=38 c, T_{\text {air outlet }}=41 c, \text { Head of water }=20 \mathrm{~mm} \\
T_{s}=\frac{\left(T_{1}+T_{2}+T_{3}+T_{4}+T_{5}+T_{6}\right)}{6}=89.66 \mathrm{c} \\
T_{a}=\frac{T_{a 1}+T_{a 2}}{2}=\frac{(38+41)}{2}=39.5 \mathrm{c} \\
Q=h A\left(h_{s}-h_{a}\right) \text { where } Q=V I=200 \times 0.40=80 \mathrm{watts}, A=\pi D L=0.05966 \mathrm{~m}^{2} \\
h=\frac{Q}{A\left(T_{s}-T_{a}\right)}=\frac{80}{0.05966(89.66-39.15)}=26.55 \mathrm{w} / \mathrm{m}^{2} \mathrm{k}
\end{gathered}
$$

3.4 Calculation of Heat Transfer Coefficient by Correlation Method

By correlation method at $T_{\text {mean }}$ temp (39.5)

Properties of air: Density $=1.110 \mathrm{~kg} / \mathrm{m}^{3}, \gamma=16.9 \times 10^{-6}$

$\mathrm{K}=0.027, P_{r}=0.69, \mathrm{~A}=$ area of inlet is $1.13 \times 10^{-3} \mathrm{~m}^{2}$

Discharge through orifice

$$
q=C_{d} A_{o} \sqrt{2 g h_{a}}
$$

Where $C_{d}=0.65, A_{o}$ is the area of orifice which is $4.9 \times 10^{-4} \mathrm{~m}^{2}$. (Diameter of orifice $=0.025 \mathrm{~m}$ )

$$
\begin{gathered}
h_{a}=\frac{\text { (density of water } * \text { head of water })}{\text { Density of air }}=\frac{1000 \times 0.020}{1.2}=16.66 \mathrm{~m} \text { (Head of air) } \\
q=0.65 \times 4.9 \times 10^{-4} \sqrt{2 \times 9.81 \times 16.66}=5.76 \times 10^{-3} \text { (Discharge in orifice) } \\
\text { Velocity }=\frac{q}{A}=\frac{5,76 \times 10^{-3}}{1.13 \times 10^{-3}}=5 \mathrm{~m} / \mathrm{s} \\
R_{e}=\frac{V D}{\gamma}=\frac{5 \times 0.038}{16.96 \times 10^{-6}}=11515
\end{gathered}
$$

$\gamma$ is kinematic viscosity obtained from data hand book properties of air which is $16.96 \times 10^{-6}$ $R_{e}=11515$ based on $R_{e}$ no correlation has been chosen that is Dittus-Boelter equation

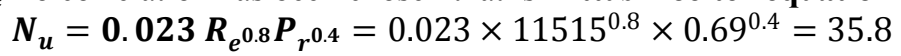

We know $N_{u}=\frac{h D}{K}$, where $\mathrm{h}$ is heat transfer coefficient, D is pipe inner diameter and $\mathrm{k}$ is thermal Conductivity of air at mean temperature obtained from properties.

$$
N_{u}=\frac{h D}{K}=h=\frac{N_{u} \times k}{D}=\frac{35.8 \times 0.027}{0.038}=25.5 \mathrm{w} / \mathrm{m}^{2} \mathrm{k}
$$

Experimental $\mathrm{h}=26.55 \mathrm{w} / \mathrm{m}^{2} \mathrm{k}$. Now validate the correlation using CFD simulation.

\subsection{CFD Analysis of Pipe}

\section{Cfd Simulation}

There are four basic steps involved in the CFD analysis of pipe. They are given as below

$>$ Creating geometry and meshing

$>$ Pre-processing

$>$ Solver

$>$ Post processing.

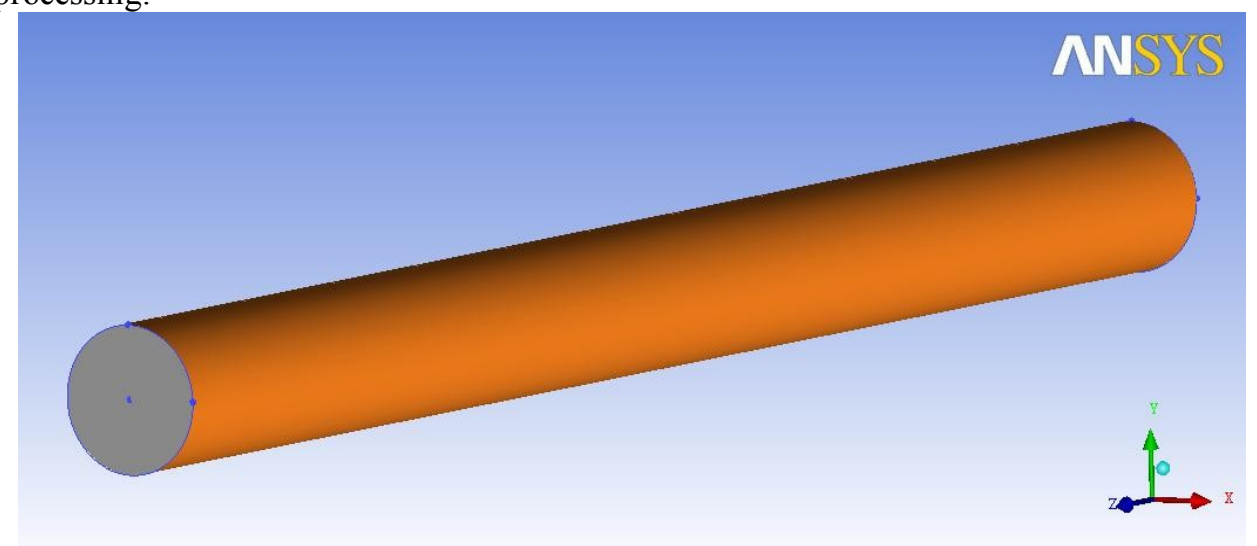

Fig. 4.1: Modelling of Pipe Using ICEM CFD 


\subsection{Geometry Model}

ANSYS ICEM is used to build a 3D geometry for CFD analysis is shown in Figure 4.2. The geometry is created and Meshed using ANSYS ICEM CFD. The length of pipe is 500mm and inner diameter is $0.038 \mathrm{~m}$.

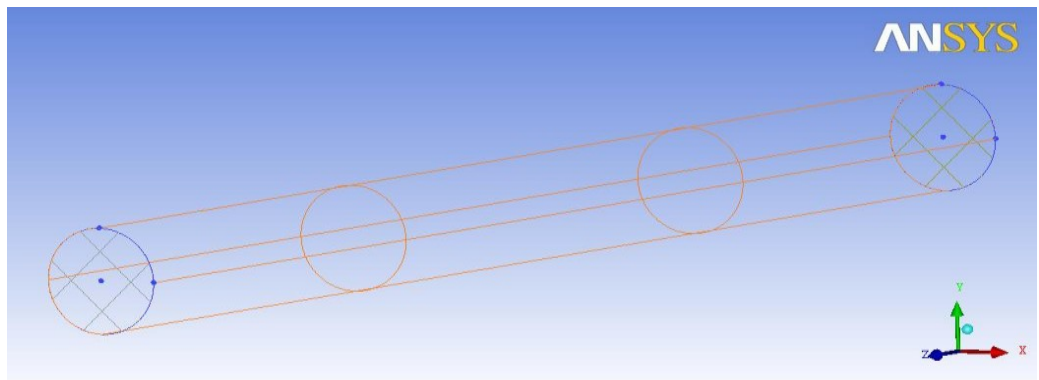

Fig. 4.2: Wire Frame of Pipe Using ICEM CFD

4.3Meshing

The computational model is created in ICEM-CFD as per the dimensions shown in Figure 4.3. Later the Tetrahedral Mesh with Smooth Transition grid is generated.

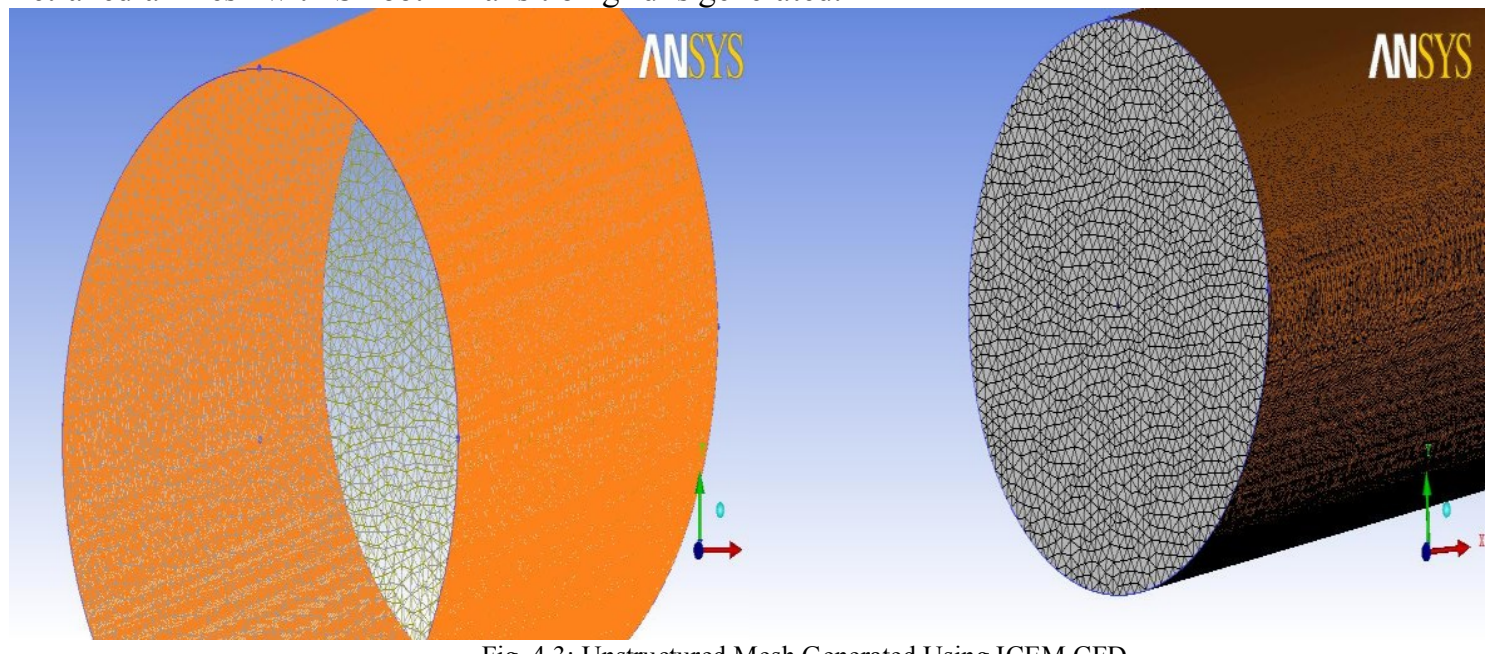

4.4 CFD Simulation in CFX-13

Fig. 4.3: Unstructured Mesh Generated Using ICEM CFD

The computational model is created in ICEM-CFD as per the dimensions shown in Figure 4.2. Later the Tetrahedral Mesh with Smooth Transition grid is generated.The solver and the boundary conditions are specified in CFX-13 i.e. used segregated solver with asymmetric space and k-epsilon for turbulent modelling. The boundary conditions and reference values are shown below.

\section{Boundary Conditions:}

$>$ Location $=$ inlet

Boundary details, subsonic

Normal speed $=5 \mathrm{~m} / \mathrm{sec}$

Medium intensity $=5 \%$

Heat transfer:

Static temp $=311 \mathrm{k}$

$>$ Location outlet

Boundary details

Relative pressure $=1 \mathrm{~Pa}$

$>$ Wall

Wall heat flux $=1350 \mathrm{w} / \mathrm{m}^{2} \mathrm{k}$

Option: no slip wall

Smooth wall 


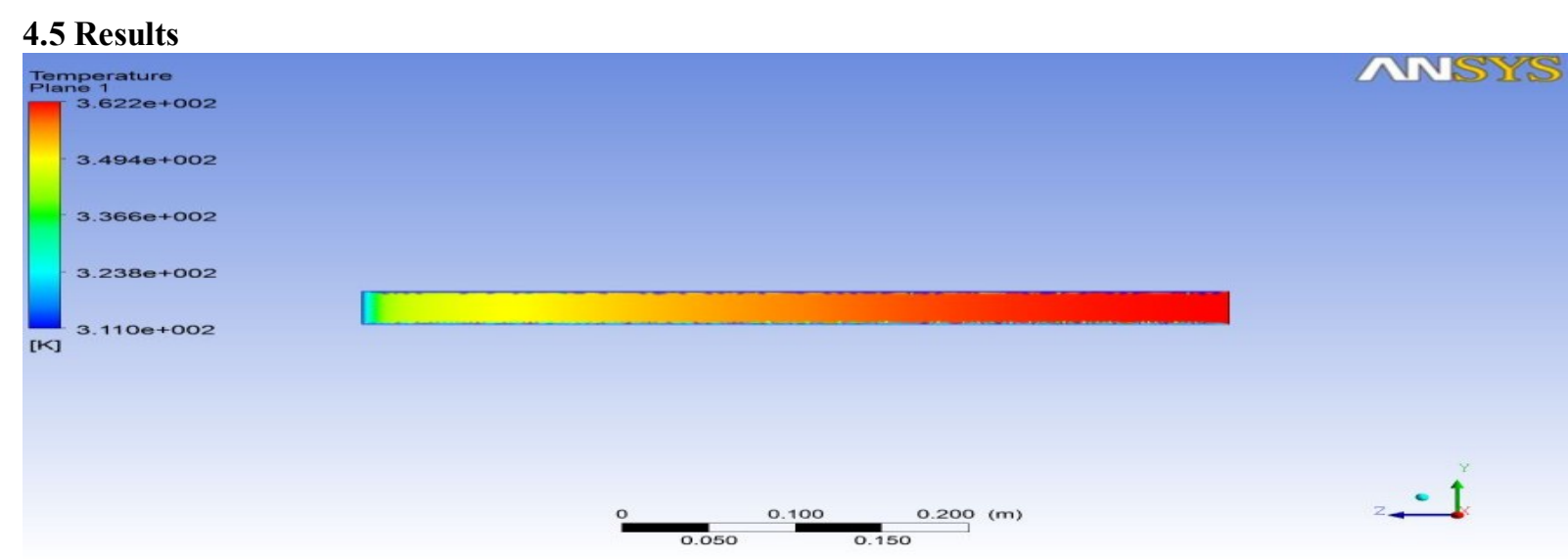

Fig. 4.4: Temperature Plane

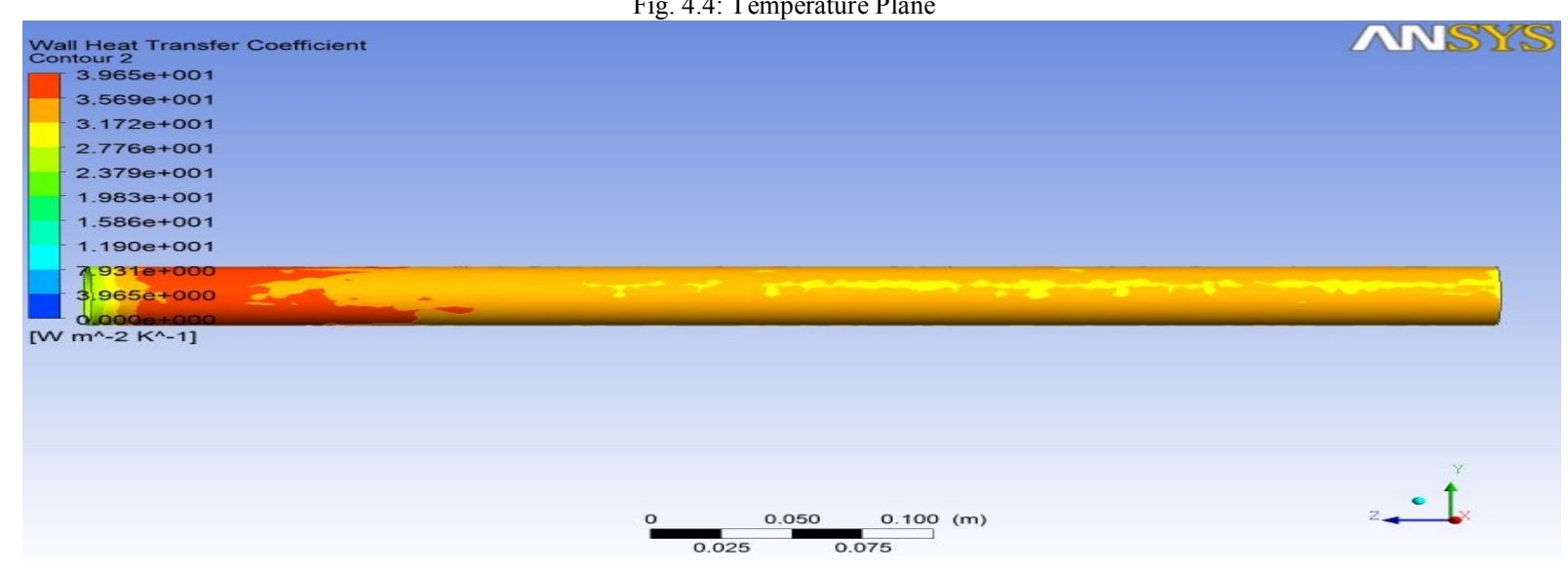

Fig. 4.5: Heat Transfer Coefficient

\section{Validation Of Experimental, Cfd And Correlation}

Experimental $\mathrm{h}=26.55 \mathrm{w} / \mathrm{m}^{2} \mathrm{k}$

Correlation $\mathrm{h}=25.5 \mathrm{w} / \mathrm{m}^{2} \mathrm{k}$

CFD simulation $\mathrm{h}=32.0 \mathrm{w} / \mathrm{m}^{2} k$ (From Figure 4.5), from this the valueobtained by CFD is very nearer to correlation and experimental hence Dittus-Boelter equation is validated.

The primary objective of this work is to determine heat transfer coefficients (local and average) for different flow geometries and this heat transfer coefficient (h) may be obtained by experimental or theoretical methods.

Theoretical methods involve solution of the boundary layer equations to get the Nusselt number. On the other hand the experimental methods involve performing heat transfer measurement under controlled laboratory conditions and correlating data in dimensionless parameters. Many correlations for finding the convective heat transfer coefficient are based on experimental data which needs uncertainty analysis, although the experiments are performed under carefully controlled conditions. The causes of the uncertainty are many. Actual situations rarely conform completely to the experimental situations for which the correlations are applicable. Whatever the value obtained by experimental, correlation and CFD simulation agree with each other with an error less than 28 $\%$. Hence Dittus-Boelter has been validated.

\section{Conclusion}

By carrying out experiment, simulation and calculation, it is conclude that these correlations give an error well within the range $28 \%$ and usually less in controlled environment. The results clearly validate the use of Dittus-Boelter correlation in many industrial applications. There are many reasons which contribute to the errors. The heat loss does account for errors, but the value of heat loss is negligible as compared to total heat flux. The heaters are local made and do not provide constant surface heat flux although it has been tried to control wattage of each heater. Secondly all sensors (temperature) are attached in a close proximity of $220 \mathrm{~V}$ AC lines coming from heaters. Therefore signals from sensors are distorted and give an error. If somehow these problems are overcome results may improve. Another thing is correlation results must be more but here it is less because this has been taking the property of air at mean temperature of inlet and out let obtained by experiment. 


\section{References}

[1] Dittus, F. W., and L. M. K. Boelter. University of California (Berkley) Pub. Eng., vol. 2., p. 443, 1930.

[2] Holman, J. P., Heat Transfer, 9th edition, McGraw Hill, p. 267-271.

[3] Diane L. Linne, Michael L. Meyer, Tim Edwards, and David A. Eitman. Evaluation of Heat Transfer and Thermal Stability of Supercritical JP-7 Fuel. NASA Technical Memorandum 107485.

[4] Incropera, Fundamentals of Heat and Mass Transfer, 5th edition, John Wiley and Sons

[5] J. R. Lamarsh\& Anthony B., Intro to Nuclear Engineering, 3rd edition, Wiley

[6] Munson, Young, Okishi, Fundamentals of Fluid Dynamics, 4th edition, Wiley

[7] Tichakorn, Forced Convection, research paper, Cornell University, Nov 2004

[8] Mechanical and Aerospace Engineering Laboratory, Forced Convection Heat Transfer, State University of New Jersey

[9] Application note, Active Filter Design, Texas instrument

[10] Application note, AN699, AN823, AN990, AN682, AN685, AN687, AN684 Microchip Technology Inc

[11] Hilpert, R. "Heat Transfer from Cylinders," Forsch. Geb. Ingenieurwes, 4:215. 1933.

[12] Incropera F. and D. De Witt. Fundamentals of Heat and Mass Transfer, 5th Edition, USA. 2002

[13] Fand, R. M. and K. K. Keswani. "A Continuous Correlation Equation for Heat Transfer from cylinders to Air in Crossflow for Reynold's Numbers from 10-2 to 2(10)5," International Journal of

a. Heat and Mass Transfer, 15:559-562. 1972

[14] Fand, R.M. and K. K. Keswani. "Recalculation of Hilpert's Constants,” Transactions of ASME,pp. 224-226. 1973.

[15] Zukauskas, A. "Heat Transfer From Tubes in Crossflow," Advances in Heat Transfer, 8:87-159.1987.

[16] Churchill, S.W. and H. H. S. Chu. "Correlating Equations for Laminar and Turbulent Free Convection From a Horizontal Cylinder," International Journal of Heat And Mass Transfer,18:1049-1053. 1975.

[17] Churchill, S. W. and M. Bernstein. "A correlating Equation for Forced Convection from Gases and Liquids to a Circular Cylinder in Crossflow," J. Heat Transfer, 99:300-306. 1977.

[18] Morgan, V. "Heat Transfer from Cylinders," Advances in Heat Transfer, 11:199-264. 1987.

[19] Manohar, K., Yarbrough, D. W. and Booth, J. R. "Measurement of Apparent Thermal Conductivity by the Thermal Probe Method," Journal of Testing and Evaluation, 28(5):345-351.2000.

[20] Coleman, H. W. and Steller, W. G. "Experimentation and Uncertainty Analysis for Engineers,"2nd Ed., John Wiley and Sons, New York, pp. 47-64 (1999). 